\author{
R.M. Balabai, D.V. Zalevskyi
}

\title{
SiGe Epitaxial Films with Dislocations for the Switchable Memory: the Accurate First-Principle Calculations
}

\begin{abstract}
Kryvyi Rih State Pedagogical University, Kryvyi Rih, 50086, Ukraine, balabai@i.ua, denys.zalevski@gmail.com
The characteristics of an electronic subsystem of the RRAM (Resistive Random Access Memory) layer constructed on the basis of epitaxial films $\mathrm{Si}_{0.9} \mathrm{Ge}_{0.1}$ with dislocations and embedded in them silver atoms are obtained by the methods of the theory of the functional of electron density and pseudopotential from the first principles. The spatial distributions of the density of valence electrons and their cross sections within the cell, the distribution of the density of electronic states, and electric charges in the vicinity of the silicon atoms in different atomic environments are calculated. It is investigated how changes in the electronic subsystem of investigated objects influence the change of their properties from non-conducting to conducting ones.

Keywords: resistive random access memory, the electron density functional, ab initio pseudopotential, electron structure, density of states.
\end{abstract}

Article acted received 14.06.2019; accepted for publication 15.09.2019.

\section{Introduction and task statement}

The peculiarity of the information technology industry is the ever-increasing demands on the components of personal computers, smartphones, tablets and other computer systems. This in turn serves as a prerequisite for researching new memory technologies with economic data storage solutions. Among the new technologies of nonvolatile memory intended for use in solid-state drives, programmable logic integrated circuits and neuromorphic calculations, random access memory (RRAM) has recently become more and more popular and is becoming more and more interesting for the research community [1-4].

RRAM (Resistive RAM) uses cell resistivity to store and read information from it. The typical structure of RRAM cells is a simple sandwich configuration of metal-isolator-metal: a dielectric layer is located between two electrodes. First, it has a high resistance [3]. For a certain effect on it (for example, applying a voltage to a certain level), there are current conducting threads, that is, in fact, it ceases to be a dielectric. When changing the polarity of the applied voltage, these conductive lines are destroyed $[5,6]$.

RRAM technology is not as simple as it would be desirable, but the production process has its own characteristics, but it is not too complicated. The process of making RRAM is that on an already prepared plate with the formed lower electrode, layers of cells are applied, their connection is carried out and the chip is completed. One can say that the main problem is not in the manufacture of chips, but in ensuring its performance and achieve the desired characteristics [7].

There are several varieties of such memory that differ in the use of different materials for the manufacture of cells. The main ones are OxRAM (Oxide-based RRAM) and CBRAM (conductivebridging RAM). Combines them with the use of two electrodes, the upper and lower, between them is the layer of the dielectric, which changes its properties, and here in it just something is the differences [8].

In CBRAM, atoms of an active metal (for example, copper or silver) are introduced into the working layer (for example, from amorphous silicon) to create conductive bridges. In this case, one of the electrodes is made of inert metal (for example, tungsten), and the second - from the chemically active (for example, copper or silver). With the appearance of voltage electrodes, metal ions are built into a bridge through which the current passes. CBRAM requires lower voltage for cell programming (Figure 1).

In [1], monocrystalline SiGe researched the epitaxial memory of random access (epiRAM). The functionality of such memory is achieved through the creation of onedimensional leading Ag threads in dislocations in the SiGe layer. The $\mathrm{Si}_{0.9} \mathrm{Ge}_{0.1}$ layer with a thickness of $60 \mathrm{~nm}$ contained a sufficient number of dislocations to ensure that the device was switched on tens of nanometers [8$10]$. 


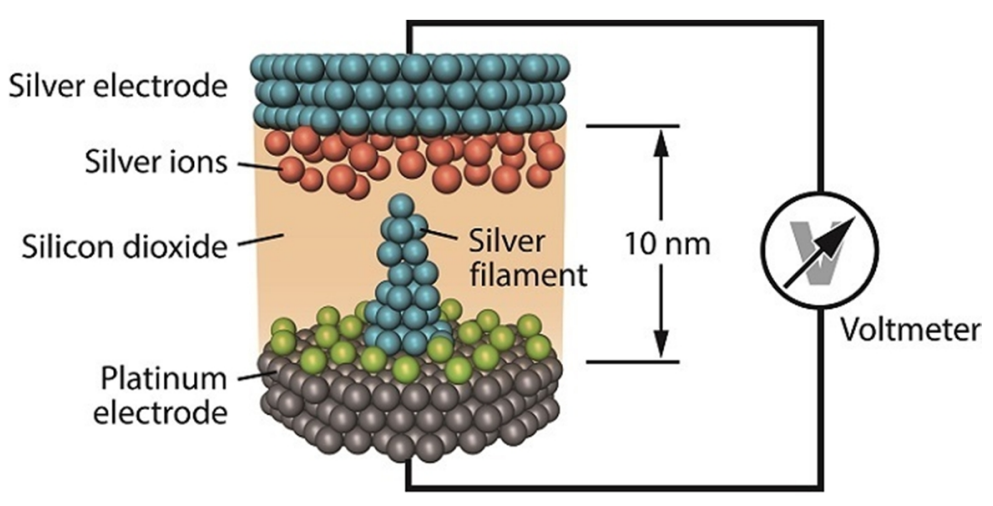

Fig. 1. CBRAM-memory cell structure [7].

In order to determine the characteristics of the RRAM working layer, which is constructed on the basis of epitaxial films of $\mathrm{Si}_{\mathrm{x}} \mathrm{Ge}_{1-\mathrm{x}}$ with dislocations with the introduction of active metal atoms, the methods of the theory of functional of electronic density and pseudopotential of the first principles were used in this paper.

\section{Methods and objects of computation}

The ground states of the electron-nucleus systems were detected by means of the self-consistent solution of the Kohn-Sham equations. Electronic variables only were determined with the atomic cores fixed. Following KohnSham, electronic density was written down in terms of occupied ortho-normal one-particle wave functions:

$$
\rho(\stackrel{r}{r})=2 \sum_{i}\left|\psi_{i}(\stackrel{r}{r})\right|^{2}
$$

The point on the surface of potential energy in the Born-Oppenheimer approximation was determined as a minimum energy functional with regard to the wave functions:

$$
E\left[\left\{\psi_{i}\right\},\left\{R_{j}\right\},\left\{\alpha_{v}\right\}\right]=\sum_{i} \int_{\Omega} d^{3} r_{i}^{*}(r)\left[-\frac{\mathrm{h}^{2}}{2 m} \nabla^{2}\right] \psi_{i}(r)+U\left[\{\rho(r)\},\left\{R_{j}\right\},\left\{\alpha_{v}\right\}\right],
$$

where $\left\{R_{j}\right\}$ are coordinates of atomic cores; $\left\{\alpha_{v}\right\}$ are any external influences on the system.

In the generally accepted formulation, minimization of the energy functional (2) with respect to one-particle orbitals with additional orthonormal constraint on the one-particle orbitals $\psi_{i}(r)$ results in Kohn-Sham oneparticle equations:

$$
\left\{-\frac{\mathrm{h}^{2}}{2 m} \nabla^{2}+\frac{\partial U}{\partial \rho(r)}\right\} \psi_{i}(\stackrel{r}{r})=\varepsilon_{i} \psi_{i}(\stackrel{r}{r})
$$

In the solution of these equations, the pseudopotential formalism was used, according to which a solid is considered as a set of valence electrons and the ion cores. In the pseudopotential approximation, the operator of the pseudopotential $\mathrm{V}_{\mathrm{PS}}$, which describes the interaction of valence electrons with the core, is small, and the corresponding pseudo-wavefunction is smooth. Pseudopotential are required to correctly represent the long range interactions of the core and to produce pseudo-wavefunction solutions that approach the full wavefunction outside a core radius $r_{c}$. In addition it is desired that a pseudopotential is transferable, this means that one and the same pseudopotential can be used in calculations of different chemical environment resulting in calculations with comparable accuracy. For example, Bachelet, Hamann and Schliiter proposed an analytic fit to the pseudopotentials. This ab initio pseudopotential is used by us.

The full crystalline potential is constructed as the sum of ion pseudopotentials that are not overlapping and associpted with ions (nucleus + core electrons), located at the $R_{S}$ positions that are periodically repeated for crystals:

$$
V_{\text {крuст }}(\stackrel{r}{r}) \rightarrow V_{P S}(\stackrel{r}{r})=\underset{p}{\underset{p}{ }} \sum_{S} V_{S} P S\left(\stackrel{r}{r}-\stackrel{r}{p}-\stackrel{r}{R_{S}}\right) \text { (4) }
$$

For nonperiodic systems, such as a thin film or a cluster the problem of lack of periodicity is circumvented by use of the supercell method. Namely, the cluster is periodically repeated but the distance between each cluster and its periodic images is so large that their interaction is negligible. The ubiquitous periodicity of the crystal (or artificial) lattice produces a periodic potential and thus imposes the same periodicity on the density (implying Bloch's Theorem). The Kohn-Sham potential of a periodic system exhibits the same periodicity as the direct lattice and the Kohn-Sham orbitals can be written in Bloch form:

$$
\psi(\underset{r}{r})=\psi_{i}\left(r_{r}^{r}, k\right)=\exp (i k \cdot r) u_{i}(r, k)
$$

where $k$ is a vector in the first Brillouin zone. The functions $u_{i}(\stackrel{r}{r}, k)$ have the periodicity of the direct lattice. The index $i$ runs over all states. The periodic 

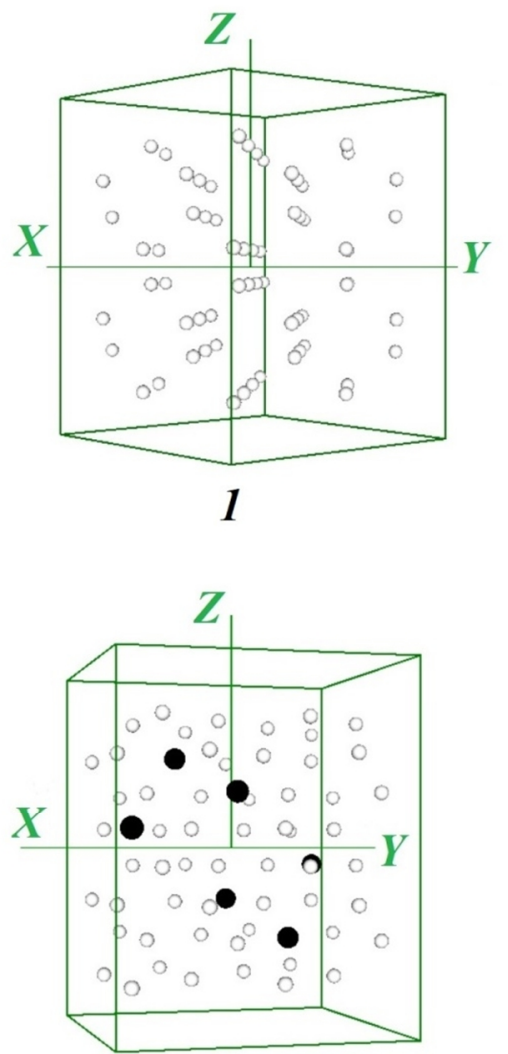

4

- amom Si
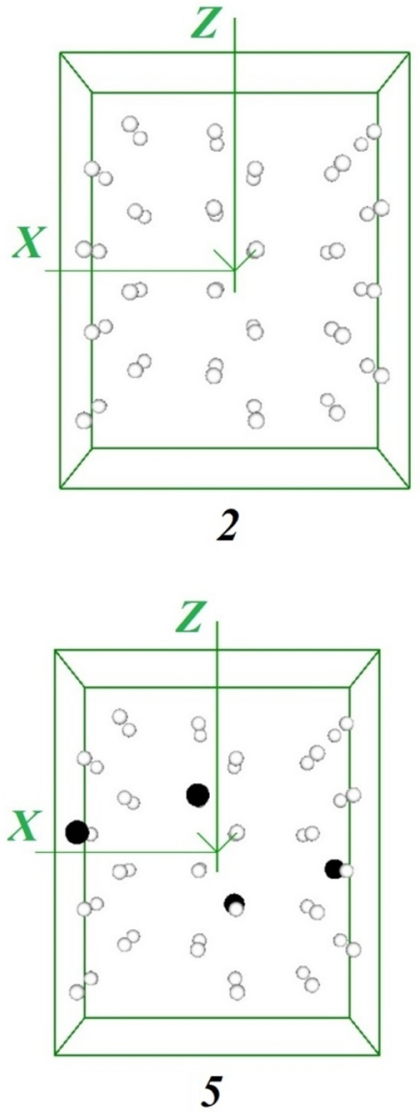

- amoм Ge
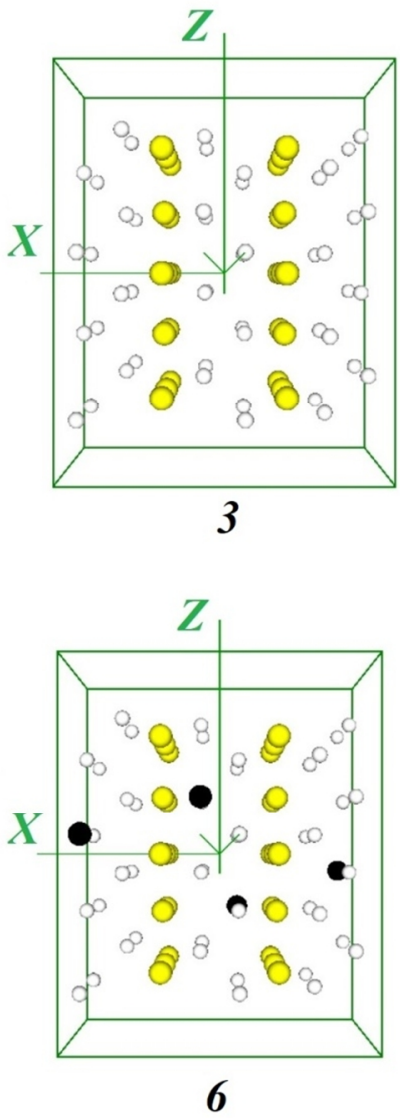

- атом Ag

Fig. 2. Supercells of an artificial super-lattice with atomic bases for different objects of computation
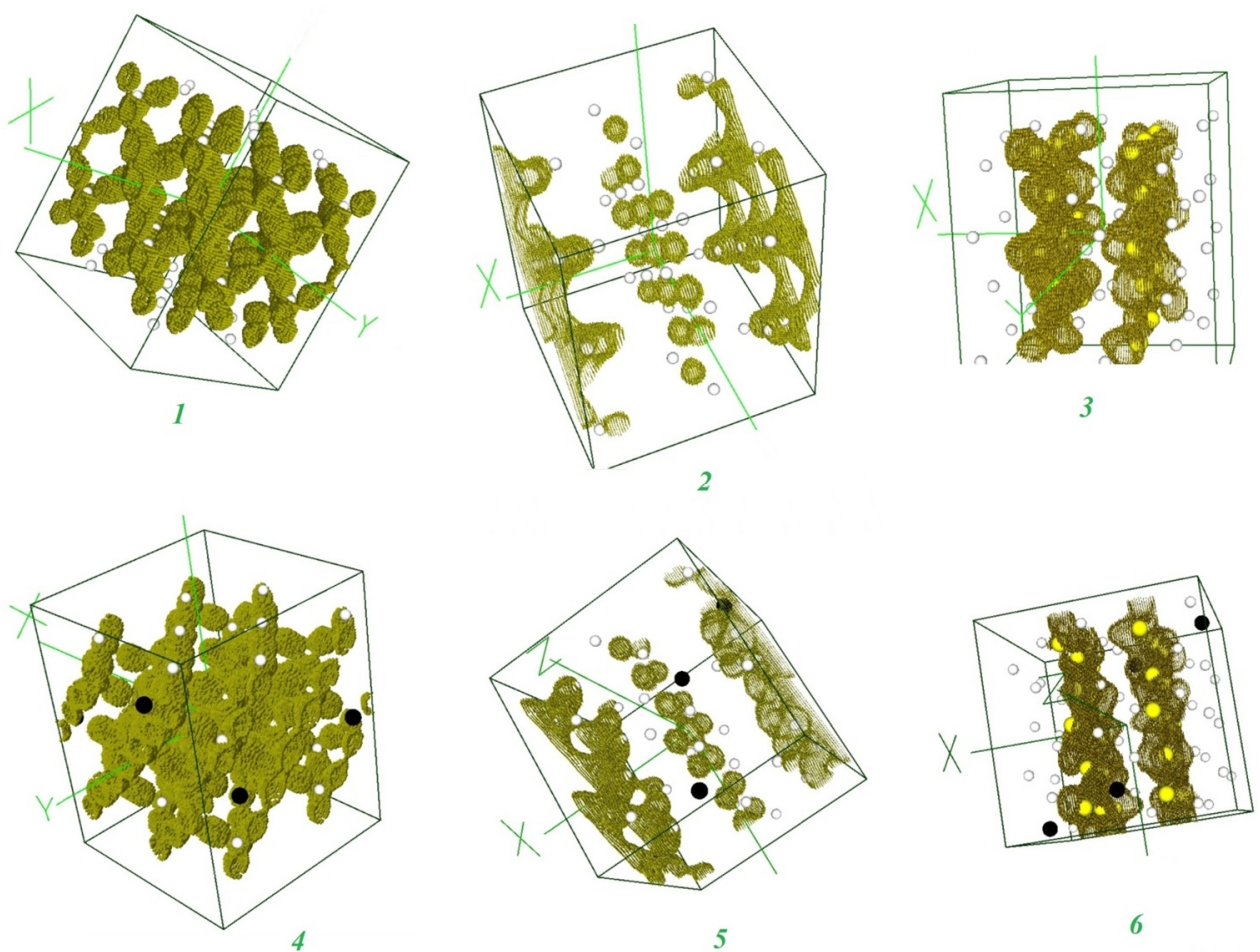

Fig. 3. Spatial distributions of the density of valence electrons within a cell for an isovalue of $0.5-0.6$ of the maximum for objects 1-6 

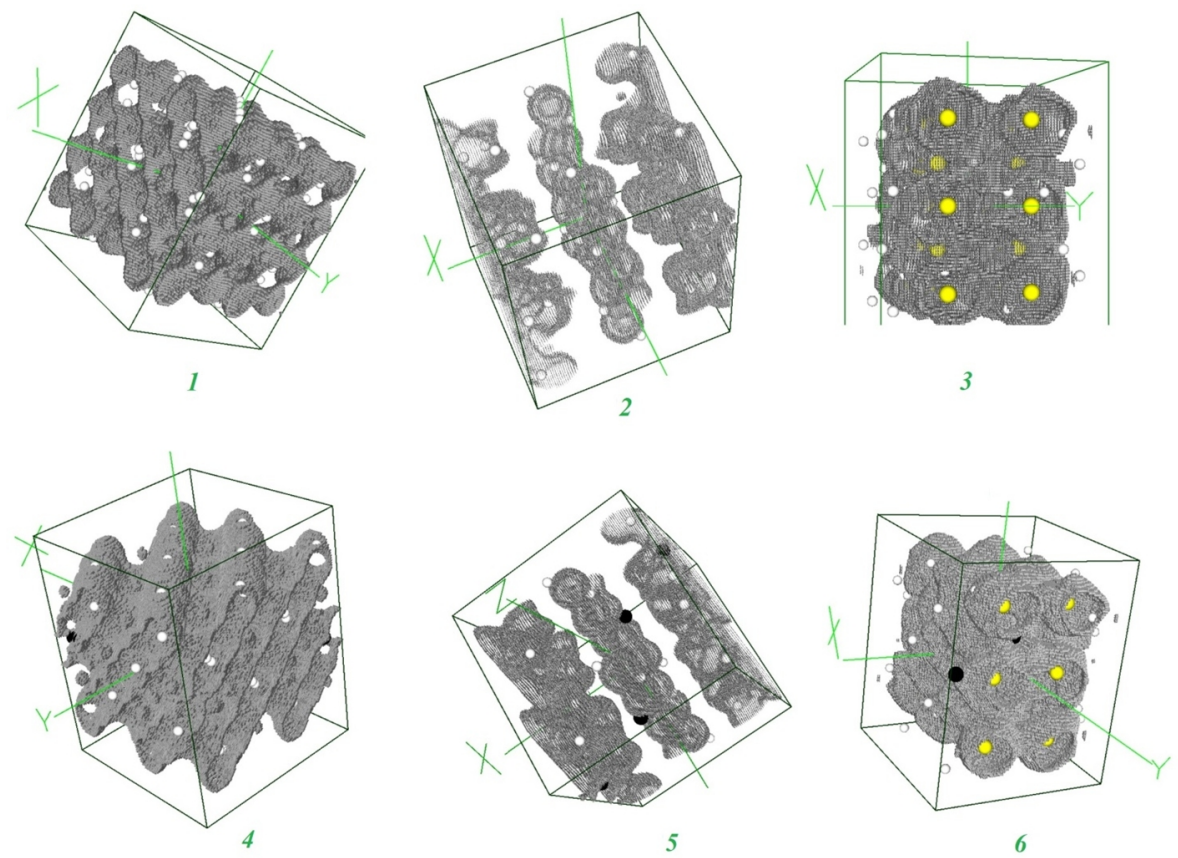

Fig. 4. Spatial distributions of the density of valence electrons within a cell for an isovalue of $0-0.2$ of the maximum for objects 1-6.

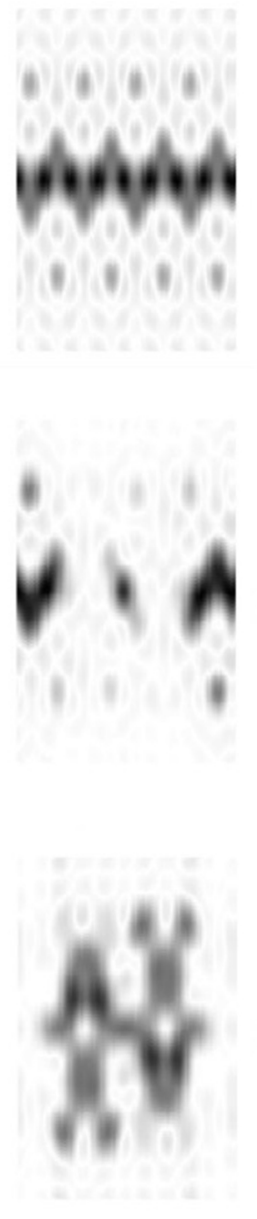

a
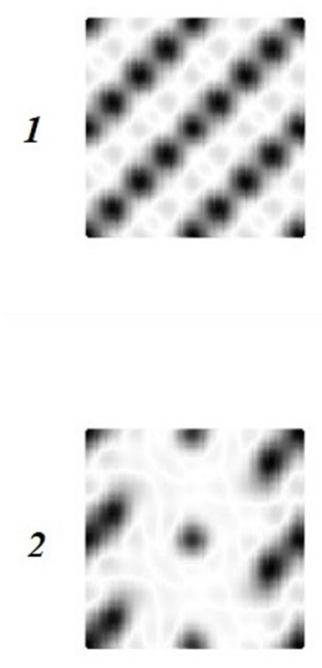

3

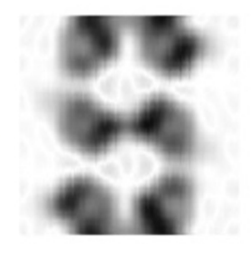

b
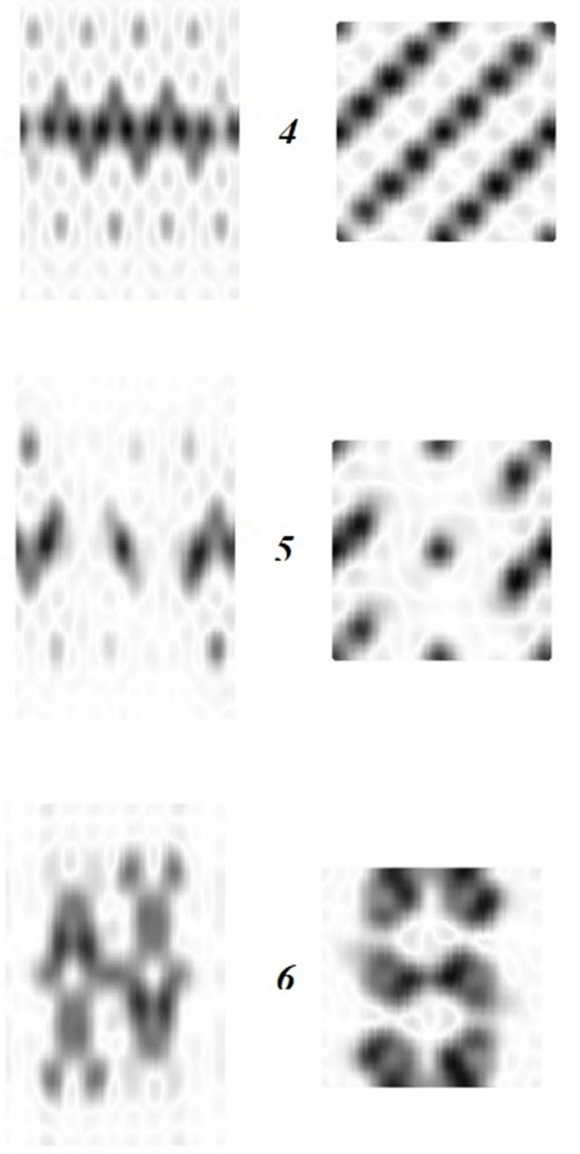

c

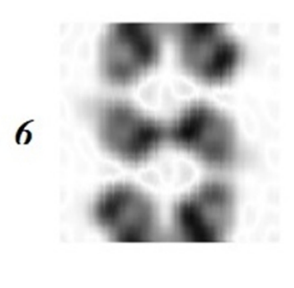

d

Fig. 5. Cross-sections of the spatial distributions of the density of valence electrons within the cell: a - section of the plane (110) for objects 1-3, b - the plane of the plane (100) for objects 1-3, c - the plane cross section (110) for objects 4-6, d - section with plane (100) for objects 4-6. 


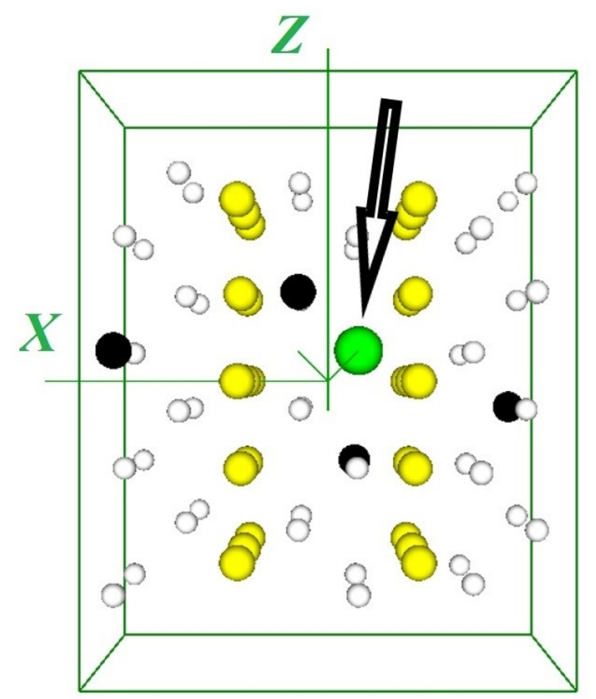

Fig. 6. The position of the silicon atom, in the vicinity of which was calculated the electric charge (the position of the atom indicated by an arrow). functions $u_{i}(r, r)$ are expanded in the plane wave basis. This heavily suggests to use plane waves as the generic basis set in order to expand the periodic part of the orbitals. Since plane waves form a complete and orthonormal set of functions, they can be used to expand orbitals according to:

$$
\Psi_{j}(\stackrel{r}{k, r} \underset{r}{r})=\frac{1}{\sqrt{N_{0}} \sqrt{\Omega}} \sum_{G} b_{J}(\stackrel{r}{k}+\stackrel{r}{G}) \exp (i(\stackrel{r}{k}+\stackrel{r}{G}) \stackrel{r}{r})(6)
$$

where $G$ is the vector in the reciprocal space, $\Omega$ is the volume of the elemental cells which consists of a periodic crystal or an artificial superlattice when reproducing nonperiodic objects.

The equation (3) after the Fourier transform to the reciprocal space has the form:

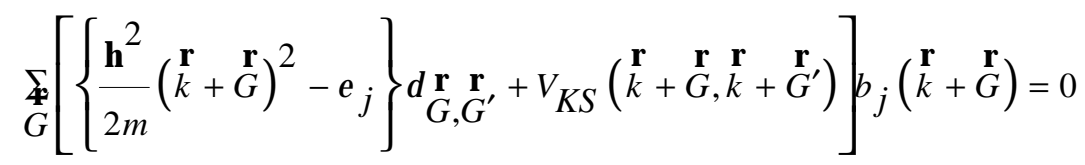

where $V_{K S}$ is the Kohn-Sham potential:

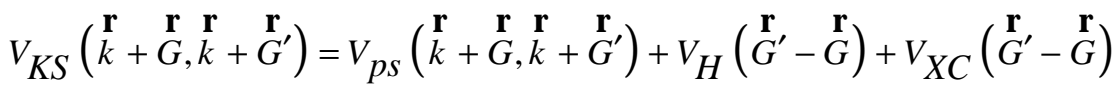

where $V_{x c}$ is the the exchange and correlation potential. To calculate it we used Ceperley-Alder's LDA approximation that has been parameterized by Perdew and Zunger. It is well-known that a choice of the exchange-correlation functional predetermines a band gap.

Nevertheless LDA in DFT do reproduce a lot of the basic physics, but without some fine tuning, they do not generally get the details of the experimental band structure correct. In this work a comparative analysis of the behavior of electron-structural characteristics of nanoobjects during the transition from one configuration to another gives the opportunity to avoid the imperfection of LDA and to reveal reliable information.

In the general case, the expressions describing the potentials of interactions are complex. The use of the atomic bases containing the inversion operation in the point symmetry group leads to the fact that the Fourier-components in the expansion of all expressions are real.

The main value in the formalism of the functional of the electron density is the charge density. It is estimated from a self-consistent solution of equations (6) which should be performed at all points of the non-reduced section of the Brillouin zone:

$$
\rho(\stackrel{r}{G})=\frac{2}{N_{T}} \underset{k}{\underset{k}{k}} \sum_{j} \sum_{\alpha \in T} \underset{G^{\prime}}{\sum} b_{j}^{*}\left(\stackrel{r}{k}+\stackrel{r}{G^{\prime}}+\alpha \stackrel{r}{G}\right) b_{j}\left(\stackrel{r}{k}+\stackrel{r}{G^{\prime}}\right)
$$

where the index $j$ runs over all occupied states, $\stackrel{r}{k}$ is a vector in the first Brillouin zone, $N_{T}$ is the number of the operators $\alpha$ in the point group $\mathrm{T}$ of the atomic basis and the factor 2 takes into account the spin degeneracy $[11,12]$.

The results of calculations were obtained using author's computer programs [13] in the form of maps of spatial distributions of the density of valence electrons and their cross sections, the density of electronic states, the width of the valence band and the band gap, and charge in the vicinity of atomic shafts.

For computing, models of the work area $\mathrm{Si}_{\mathrm{x}} \mathrm{Ge}_{1-\mathrm{x}}$ of the epitaxial RAM were created. Since the computation algorithm presupposes the presence of a system of translational symmetry, a tetragonal type super-lattice cell with parameters a, b $=10.86 \AA$ was created. When selecting a primitive cell parameter in the crystallographic direction $\mathrm{c}$, the need to avoid interaction between the atoms of the transmitted base is taken into account. The parameter $\mathrm{c}=13.57 \AA$ was chosen. The atomic basis of supercell was created depending on the object of the calculation. By translating the cell, an infinite film $\mathrm{Si}_{\mathrm{x}} \mathrm{Ge}_{1-\mathrm{x}}$ was obtained, parallel to the crystallographic axes a, b. Here is a description of model objects (Figure 2):

Object 1: an infinite film of silicon, a thickness of $10.86 \AA$; The atomic basis of supercell contains $64 \mathrm{Si}$ 
Electric charges in the vicinity of the core of an atom of silicon with a radius of $1.32 \AA$ at different atomic environments

\begin{tabular}{|c|c|}
\hline Number and name of the object & $\begin{array}{l}\text { Charge in the } \\
\text { vicinity of the } \\
\text { silicon atom } \\
\text { body, shown in } \\
\text { the picture, ee }\end{array}$ \\
\hline $\begin{array}{l}\text { Object 1: an infinite film of silicon, a thickness of } 10.86 \AA \text {; The atomic basis of supercell } \\
\text { contains } 64 \mathrm{Si} \text { atoms; }\end{array}$ & -3.8829 \\
\hline $\begin{array}{l}\text { Object 2: an infinite film of silicon with dislocations perpendicular to the plane (100); the } \\
\text { atomic basis of supercell contains } 48 \mathrm{Si} \text { atoms; }\end{array}$ & -0.0089 \\
\hline $\begin{array}{l}\text { Object 3: an infinite film of silicon with dislocations, which are completely filled with silver } \\
\text { with the arrangement of atoms, as in a crystal; The atomic basis of the supercell contained } 48 \\
\text { Si atoms and } 26 \mathrm{Ag} \text { atoms; }\end{array}$ & -7.9858 \\
\hline $\begin{array}{l}\text { Object 4: infinite film of solid solution } \mathrm{Si}_{0.9} \mathrm{Ge}_{0.1} \text { (mechanically stressed due to application of } \\
\text { crystallographic parameters inherent to silicon crystalline solid solution); The atomic basis of } \\
\text { the supercell contains } 58 \mathrm{Si} \text { atoms and } 6 \mathrm{Ge} \text { atoms; }\end{array}$ & $-3,8325$ \\
\hline $\begin{array}{l}\text { Object 5: an infinite film of } \mathrm{Si}_{0.9} \mathrm{Ge}_{0.1} \text { solid solution (mechanically stressed due to the } \\
\text { application of crystallographic parameters inherent to a crystal of silicon to a solid solution) } \\
\text { with dislocations perpendicular to the plane (100); The atomic basis of the supercell } \\
\text { contained } 44 \mathrm{Si} \text { atoms and } 4 \mathrm{Ge} \text { atoms; }\end{array}$ & 0.3036 \\
\hline $\begin{array}{l}\text { Object 6: an infinite film of } \mathrm{Si}_{0.9} \mathrm{Ge}_{0.1} \text { solid solution (mechanically stressed due to the } \\
\text { application of a crystallographic parameter to the solid solution inherent to a silicon crystal) } \\
\text { with dislocations perpendicular to the plane }(100) \text {, which are completely filled with silver } \\
\text { with the arrangement of atoms in the crystal ; The atomic basis of the supercell contains } 44 \mathrm{Si} \\
\text { atoms, } 4 \mathrm{Ge} \text { atoms and } 26 \mathrm{Ag} \text { atoms; }\end{array}$ & -7.7102 \\
\hline
\end{tabular}
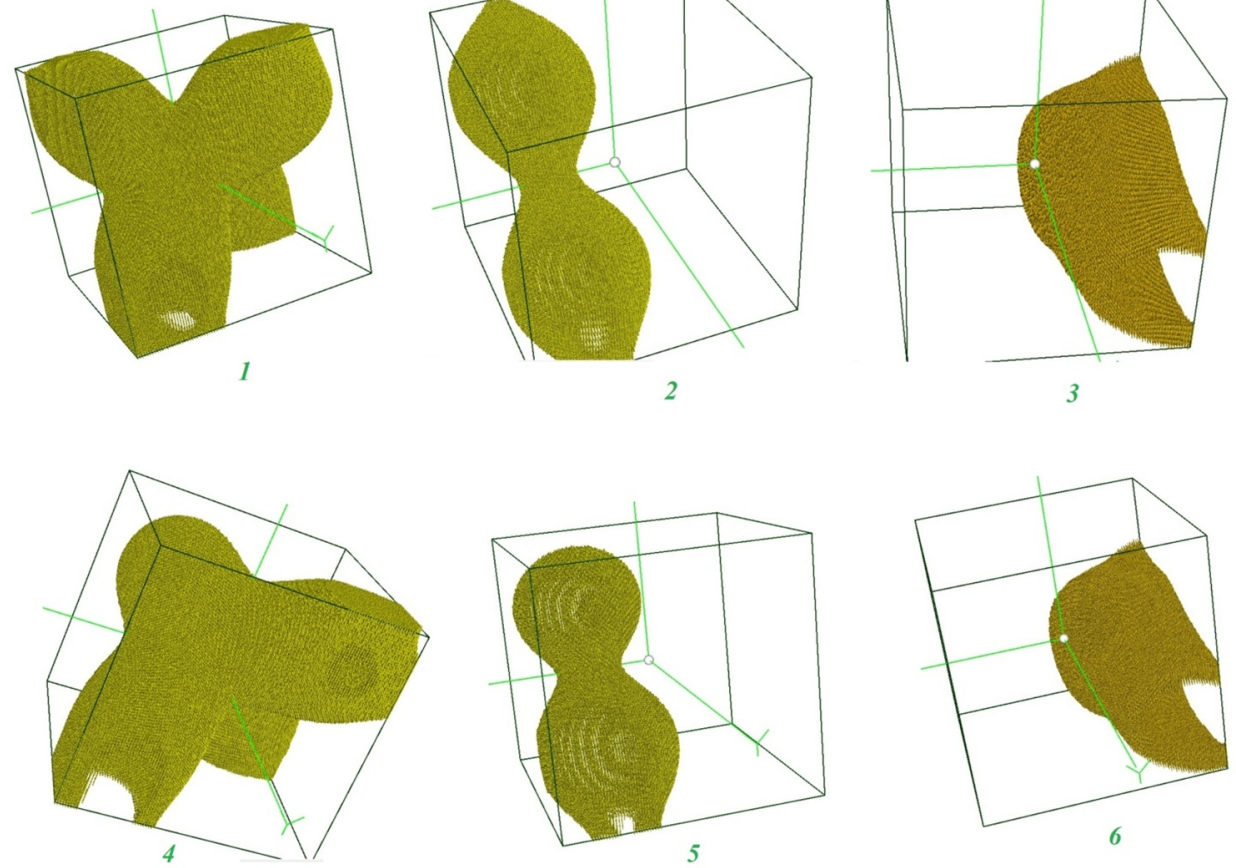

Fig. 7. Spatial distribution of the density of valence electrons in the vicinity of the silicon atom for which the electric charge was calculated, for an identification of $0.5-0.6$ of the maximum in objects 1-6. atoms;

Object 2: an infinite film of silicon with dislocations perpendicular to the plane (100); the atomic basis of supercell contains $48 \mathrm{Si}$ atoms;

Object 3: an infinite film of silicon with dislocations, which are completely filled with silver with the 
arrangement of atoms, as in a crystal; The atomic basis of the supercell contained $48 \mathrm{Si}$ atoms and $26 \mathrm{Ag}$ atoms;

Object 4: infinite film of solid solution $\mathrm{Si}_{0.9} \mathrm{Ge}_{0.1}$ (mechanically stressed due to application of crystallographic parameters inherent to silicon crystalline solid solution); The atomic basis of the supercell contains $58 \mathrm{Si}$ atoms and $6 \mathrm{Ge}$ atoms;

Object 5: an infinite film of $\mathrm{Si}_{0.9} \mathrm{Ge}_{0.1}$ solid solution (mechanically stressed due to the application of crystallographic parameters inherent to a crystal of silicon to a solid solution) with dislocations perpendicular to the plane (100); The atomic basis of the supercell contained $44 \mathrm{Si}$ atoms and $4 \mathrm{Ge}$ atoms;

Object 6: an infinite film of $\mathrm{Si}_{0.9} \mathrm{Ge}_{0.1}$ solid solution (mechanically stressed due to the application of a crystallographic parameter to the solid solution inherent to a silicon crystal) with dislocations perpendicular to the plane (100), which are completely filled with silver with

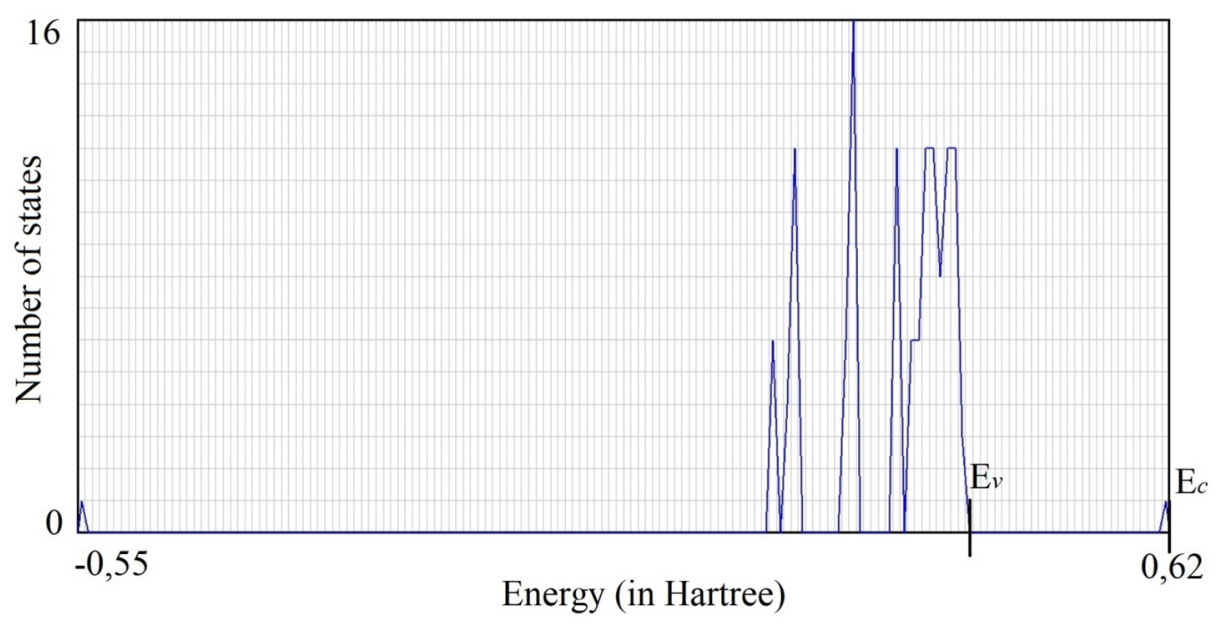

Fig. 8. Density of electronic states indicating valence and conduction zones of silicon crystal.

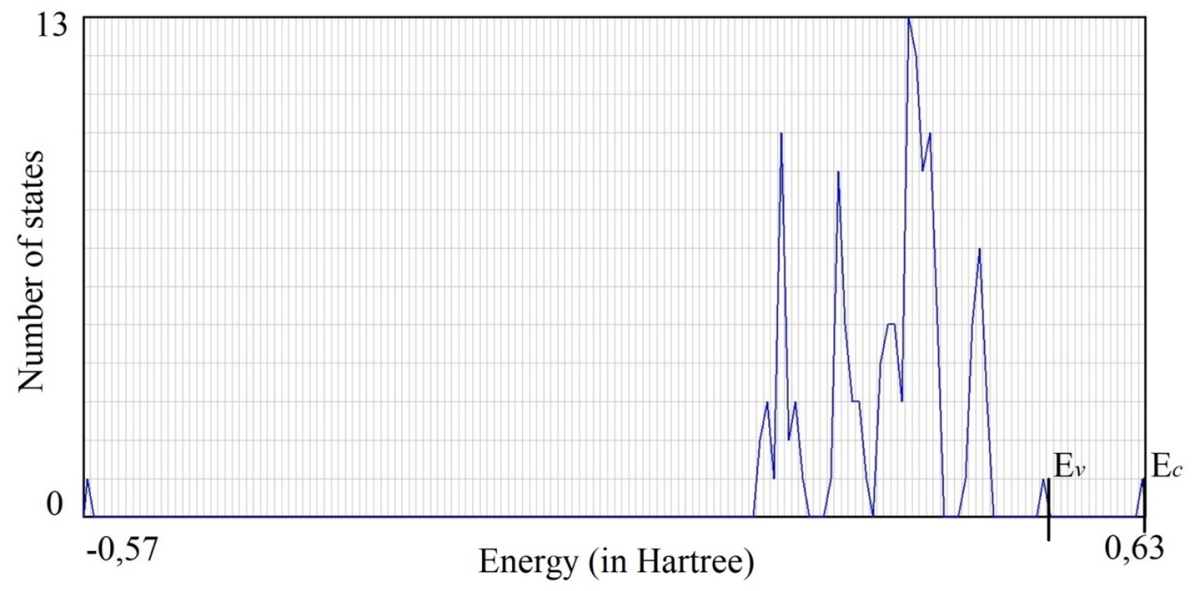

Fig. 9. Density of electronic states indicating valence and conduction zones of a solid solution $\mathrm{Si}_{0.9} \mathrm{Ge}_{0.1}$.

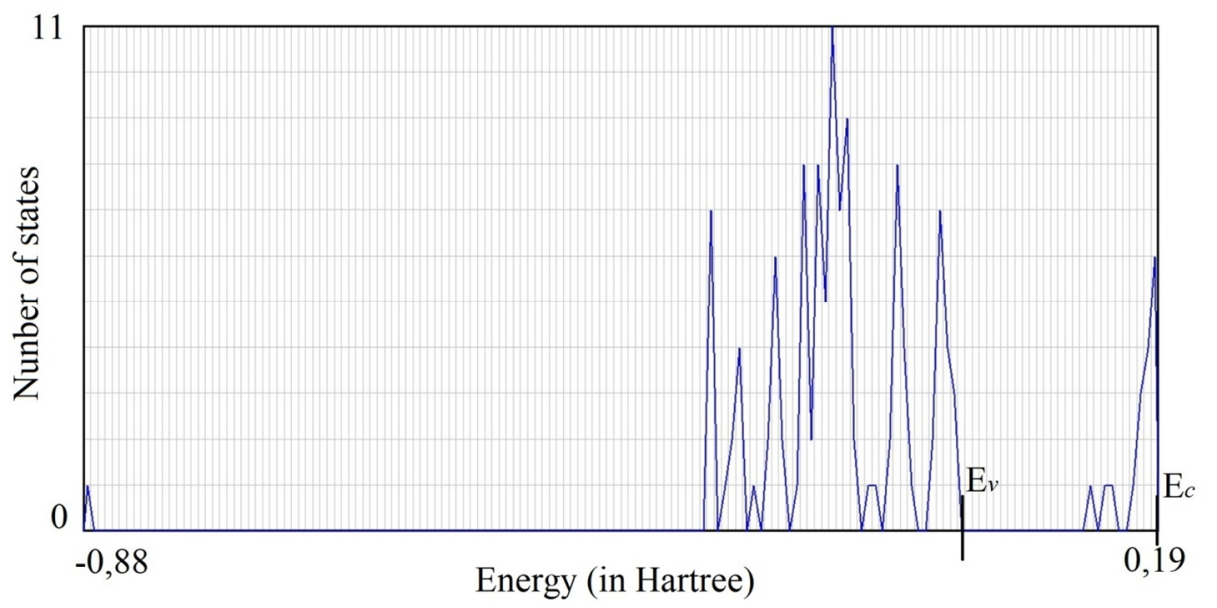

Fig. 10. Density of electronic states indicating valence and conduction zones for a silicon film. 
the arrangement of atoms in the crystal ; The atomic basis of the supercell contains $44 \mathrm{Si}$ atoms, $4 \mathrm{Ge}$ atoms and $26 \mathrm{Ag}$ atoms;

\section{Results of computation and discussion}

Figs 3, 4 show the calculated spatial distributions of the density of valence electrons and their cross sections
(Fig. 5) within the cell. Also, electric charges were calculated in the vicinity of the silicon atoms core with a radius of $1.32 \AA$ under different atomic environments (Table 1), namely: surrounded by their own atoms in a film, surrounded by their own atoms and atoms in a film in $\mathrm{Si}_{0.9} \mathrm{Ge}_{0.1}$ solid solution, on the boundary with the dislocation and on the border with a dislocation filled with silver atoms (the position of the silicon atom is shown in Figure 6). The characteristic distribution of valence electrons with a maximum along the direction is

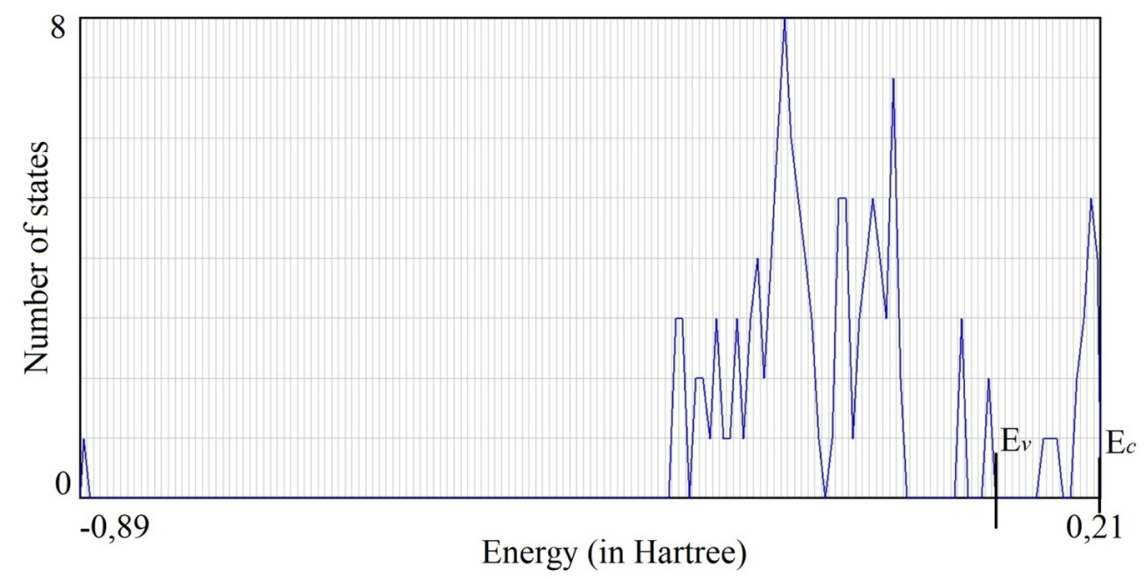

Fig. 11. Density of electron states with indication of valence and conduction zones for a $\mathrm{Si}_{0.9} \mathrm{Ge}_{0.1}$ solid solution film.

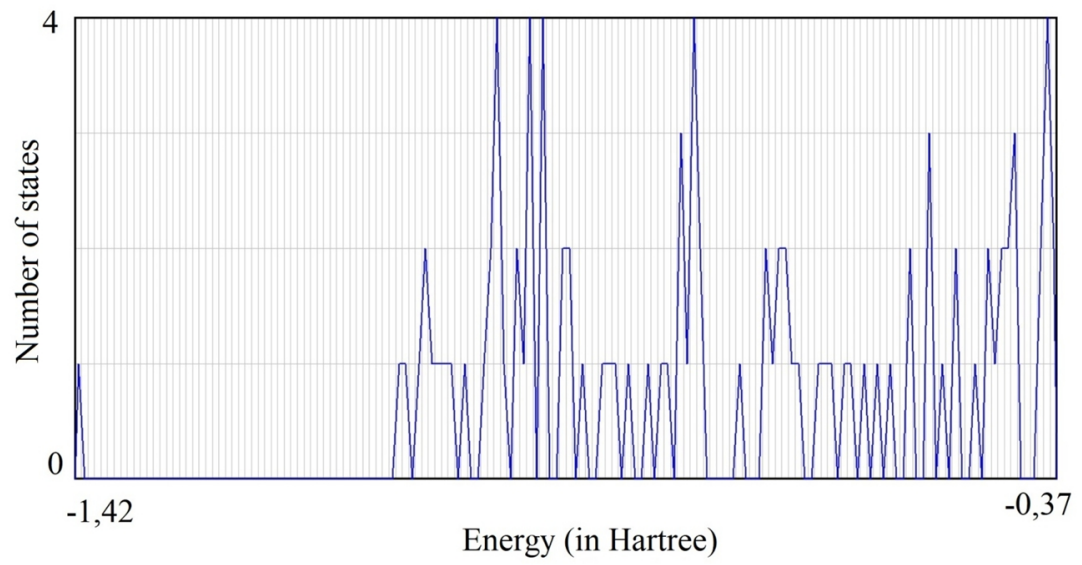

Fig. 12. Density of electronic states for a silicon film with dislocations.

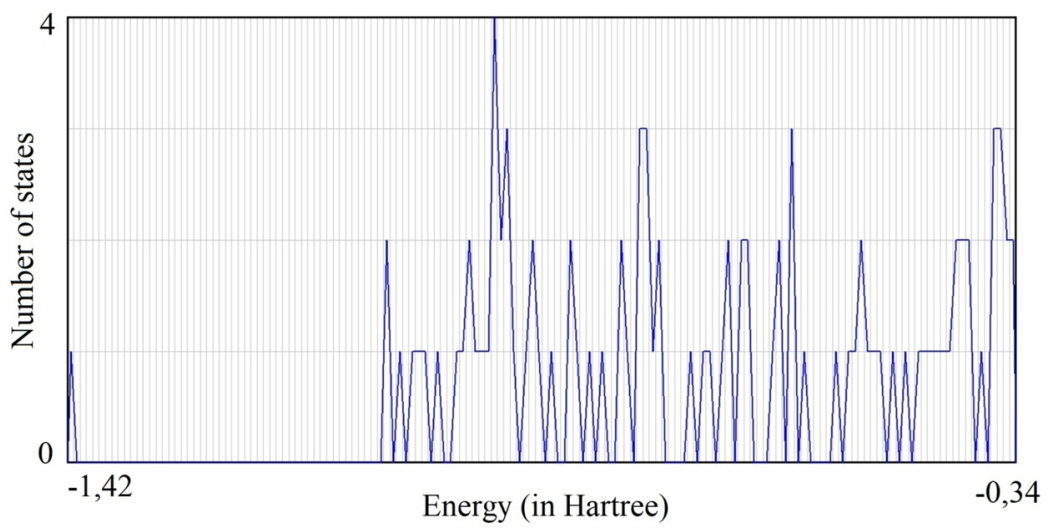

Fig. 13. Density of electron states for $\mathrm{Si}_{0.9} \mathrm{Ge}_{0.1}$ solid solution film with dislocations. 
evident for the diamond-type chemical bond [111]. The introduction of germanium atoms into the crystal of silicon or the removal of a part of the atoms from the film's mass in the formation of the dislocation, or the insertion into the void of the dislocation of silver atoms is reflected, respectively, in the distribution maps of the density of valence electrons and the values of electrical charges.

Analyzing the distribution of the density of electronic states for the investigated objects, one can point out that change in the organization of the atomic structure of objects lead to changes in the organization of distributions.

Listed in Fig. 8 distribution for the crystal Si shows a characteristic organization in which the valence band ceiling is clearly allocated, the bottom of the conduction band, which makes it possible to fix the presence of the bandgap. It is seen that the valence band consists of 4 sub-zones, which corresponds to $\mathrm{sp}^{3}$-hybridization.

However, a mechanically strong $\mathrm{Si}_{0.9} \mathrm{Ge}_{0.1}$ solid solution has a special structure of valence sub-regions - it is possible to allocate 6 sub-regions, in contrast to the defect-free crystal of silicon (Fig. 9). In this case, the band gap is clearly fixed and has a width almost half the size of the silicon crystal.

For films of silicon, the appearance of states in the band gap (Fig. 10) is demonstrated, due to the presence of incomplete bonds in the surface atoms of the film. For the atomic basis used in the simulation of films bounded by two surfaces of the type (100), 16 atoms were superficial, for which 2 electrons did not participate in the creation of covalent bonds, that is, formed 32 unsolved ligaments, due to which 16 states appeared in the band gap (ignoring spins allowed the location of two electrons at one energy level). These 16 states corresponding to torn bonds are located near the bottom of the conduction band (see Fig. 10). In this case, the width of the band gap almost coincides with the value obtained for the crystal.

Regarding the film of $\mathrm{Si}_{0.9} \mathrm{Ge}_{0.1}$ solid solution, the energy states associated with the incomplete bonds, similar to silicon films, appear in the band gap (Fig. 11).

In the presence of films in dislocations, the spectrum of the distribution of electronic states becomes linear,

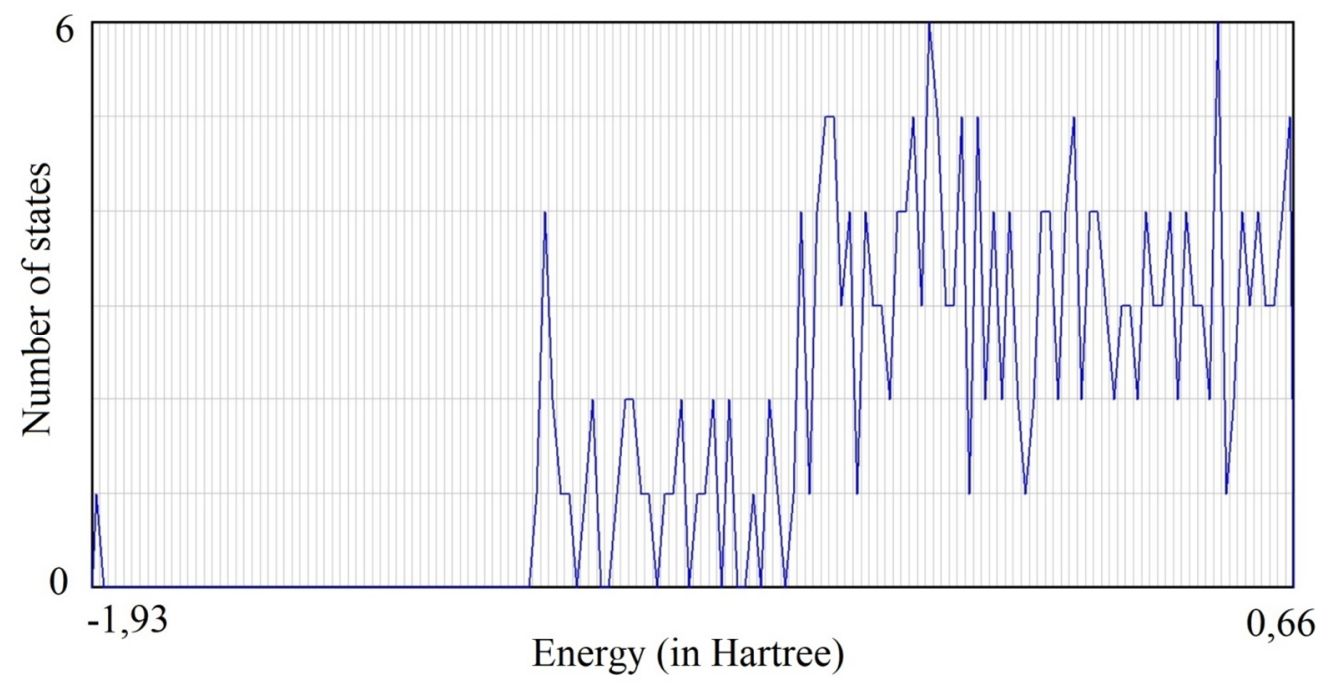

Fig. 14. Density of electronic states for a silicon film with dislocations filled with silver atoms.

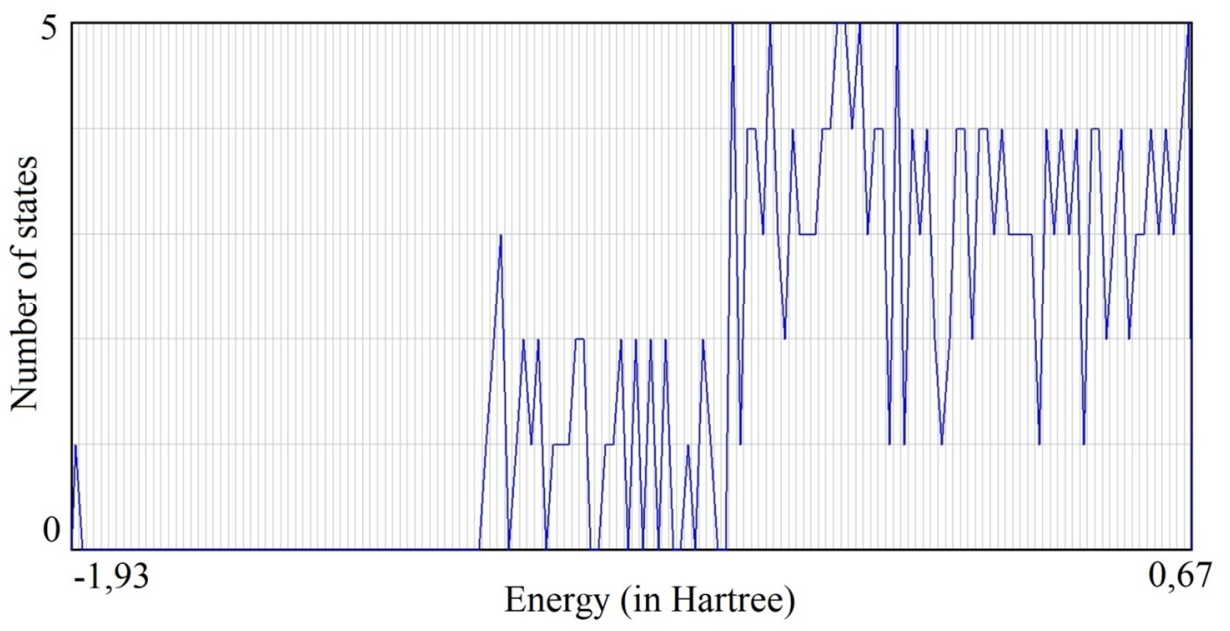

Fig. 15. Density of electron states for a film of a solid solution $\mathrm{Si}_{0.9} \mathrm{Ge}_{0.1}$ with dislocations filled with silver atoms. 
which is characteristic of molecules (Fig. 11, 12). Such a transformation of the distribution of states in which most of the permissible states can be filled by two electrons, provided that the ignoring of the spin in the calculations can be explained by the fact that when a silicon film or $\mathrm{Si}_{0.9} \mathrm{Ge}_{0.1}$ solid solution is dislocated, a family of parallelspaced nanowires is created for which such the picture of the distribution of electronic states is characteristic.

When the dislocations are filled with silver, the character of the distribution of the density of electronic states indicates that the object under investigation has metallic properties, since the band gap is absent (Fig. 13, 14).

Consequently, the transformation of films of silicon or films of a solid solution into films with dislocations followed by the filling of their silver atoms is accompanied by a significant change in their electronic properties: from non-conducting to conducting.

\section{Conclusions}

The methods of the theory of the functional of electron density and pseudopotential from the first principles obtained the characteristics of an electronic subsystem of the RRAM (Resistive Random Access Memory) layer constructed on the basis of epitaxial films $\mathrm{Si}_{0.9} \mathrm{Ge}_{0.1}$ with dislocations and embedded in them silver atoms.

The transformation of silicon films or films of a solid solution into films with dislocations followed by the filling of their silver atoms is accompanied by a significant change in their electronic properties: from non-conductive to conductive, which allows controlling the cell's state of resistive memory.

Balabai R.M. - Professor, Doctor of Science;

Zalevskyi D.V. - Postgraduate student of the Department of Physics and Methods of her teaching.

[1] Shinhyun Choi et al., Nature Materials 17, 335 (2018).

[2] Y. Burgt et al., Nat. Mater. 16, 414 (2017).

[3] Z. Wang et al., Nat. Mater. 16, 101 (2016).

[4] K.-H. Kim et al., Nano Lett. 12, 389 (2012).

[5] Y. Yang et al., Nat. Commun. 5, 377 (2014).

[6] S.H. Jo, K.H. Kim, W. Lu, Nano Lett. 9, 870 (2009).

[7] Y. Yang et al., Nat. Commun. 3, 732 (2012).

[8] K. Krishnan, T. Tsuruoka, C. Mannequin, \& M. Aono, Adv. Mater. 28, 640 (2016).

[9] D.C. Houghton, J. Appl. Phys. 70, 2136 (1991).

[10] F. Rollert, N.A. Stolwijk, \& H. Mehrer, J. Phys. D 20, 1148 (1987).

[11] N. Yakovkin, P.A. Dowben, Surface Review and Letters 14(3), 481 (2007).

[12] E. S. Kryachko, E.V. Ludeña, Physics Reports 544, 123 (2014).

[13] $\mathrm{Ab}$ initio calculation [E-resource] - Mode access to the resource: http://sites.google.com/a/kdpu.edu.ua/calculationphysics.

\author{
Р.М. Балабай, Д.В. Залевський
}

\title{
Епітаксіальні плівки SiGe $з$ дислокаціями для пам'яті з можливістю перемикання: точні розрахунки з перших принципів
}

Криворізький державний педагогічний університет 50086, м. Кривий Piz, balabai@i.ua, denys.zalevski@gmail.com

\begin{abstract}
Методами теорії функціоналу електронної густини і псевдопотенціалу із перших принципів отримані характеристики електронної підсистеми робочого шару RRAM (Resistive Random Access Memory), що побудований на основі епітаксіальних плівок $\mathrm{Si}_{0,9} \mathrm{Ge}_{0,1} 3$ дислокаціями та впровадженими в них атомами срібла. Розраховано просторові розподіли густини валентних електронів та їх перерізи в межах комірки, розподіл густини електронних станів, електричні заряди в околі остова атома кремнію при різних атомних оточеннях. Досліджено, як зміни в електронній підсистемі досліджуваних об’ єктів впливають на зміну їх властивостей від непровідних до провідних.
\end{abstract}

Ключові слова: резистивна пам'ять довільного доступу, функціонал електронної густини, псевдопотенціал із перших принципів, електронна структура, густина електронних станів. 